\title{
Anatomical variations of the sternal angle and anomalies of adult human sterna from the Galloway osteological collection at Makerere University Anatomy Department
}

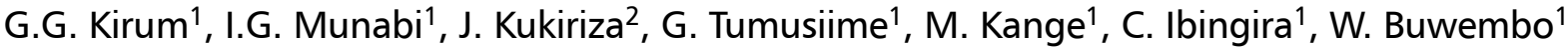 \\ ${ }^{1}$ Department of Anatomy, School of Biomedical Sciences, College of Health Sciences, Makerere University, Uganda \\ ${ }^{2}$ Department of Anatomy, Earnest Cook Ultrasound Research and Education Institute (ECUREI), Uganda \\ [Received: 13 January 2017; Accepted: 13 March 2017]
}

Background: Anatomical variations of the sternal angle and anomalies of the sternum are unique happenings of major clinical significance. It is known that misplaced sternal angles may lead to inaccurate counting of ribs and create challenges with intercostal nerve blocks and needle thoracostomies. Sternal foramina may pose a great hazard during sternal puncture, due to inadvertent cardiac or great vessel injury. These sternal variations and anomalies are rarely reported among Africans. The aim of this study was to determine the anatomical variations of the sternal angle and anomalies of the sternum among adult dry human sterna at the Galloway osteological collection, Makerere University, Uganda.

Materials and methods: This was a descriptive cross sectional study in which quantitative and qualitative data were collected. The study examined 85 adult human sterna at the Department of Anatomy, Makerere University. Univariate and bivariate analyses were done using SPSS 21.0 for Windows.

Results: Over 40\% (36/85) of the specimens had variations in size, location and fusion of the sternal angle. There was no significant difference in the mean size of the sternal angle in males at $163.4 \pm 6.7^{\circ}$ compared with $165.0 \pm 6.4^{\circ}$ in females ( $p=0.481$ ). Of the 85 specimens examined, only 21 (24.7\%) had a xiphoid process. The most frequent sternal anomalies were bifid xiphoid process 42.9\% (9/21) and sternal foramen 12.9\% (11/85).

Conclusions: Sternal variations and anomalies are prevalent in the Galloway osteological collection and there is need for increased awareness of these findings as they may determine the accuracy of clinical and other procedures in the thoracic region. (Folia Morphol 2017; 76, 4: 689-694)

Key words: abnormal sternum, physical examination, sternal fractures, sternal puncture, sternal imaging

\section{INTRODUCTION}

The sternum, a flat bone located in the middle of the chest, forms part of the anterior thoracic wall overlying the heart and great vessels in the middle mediastinum. It consists of three parts: manubrium, body and xiphoid process. The manubrium, the superior part of the sternum, is located anterior to third and fourth thoracic vertebrae and is somewhat 
triangular in shape. The body of the sternum is located anterior to fifth and ninth thoracic vertebrae. It is longer, thinner and narrower than the manubrium, but its width varies owing to the scalloping of its lateral borders by the costal notches [15]. The xiphoid process is a thin sword-shaped process and is the smallest and most variable part of the sternum. Its caudal end is related to the central tendon of the diaphragm and inferior border of the heart [24]. The manubrium and body lie in slightly different planes; hence, their junction forms a projecting sternal angle or angle of Louis, named after a French Surgeon and Physiologist who first described it [15]. A misplaced sternal angle is one that does not correspond to the second costal notch; while an additional sternal symphysis means more than one sternal symphysis, the extra ones being misplaced. Sternal foramina and clefts are openings or defects frequently manifesting at the inferior parts of the sternum. Whereas foramina are round or oval in shape, clefts are midline longitudinal defects $[7,8]$.

Anatomical variations of the sternal angle are unique happenings of major clinical significance. For instance, a misplaced sternal angle may cause inaccurate counting of ribs thereby complicating intercostal nerve blocks, needle thoracostomies and physical examination of the chest. A misplaced sternal angle is also associated with increased risk of sternal fractures in blunt chest trauma [24]. An additional sternal symphysis can mimic a fracture, traumatic fissure or an osteolytic lesion during sternal imaging $[4,27]$. Radiologists should be aware and suspicious of this variant as a potential differential diagnosis. Sternal anomalies like foramina and clefts are also known to be clinically important. Fatal cardiac tamponade, resulting from congenital sternal foramen located in the inferior part of the sternum, has been reported during sternal puncture for bone marrow biopsy or acupuncture [11, 26]. The awareness of the presence of sternal foramen to prevent this fatal complication is paramount. This can be achieved by avoiding the inferior part of the sternal body during bone marrow aspiration. A sternal cleft is a rare congenital defect of the anterior chest wall and is the result of a failed midline fusion of the sternum. There are complete and incomplete forms depending on the degree of separation. The clinical significance is that it leaves the heart and great vessels unprotected [9] and could also be mistaken for a sternal fracture [6].

Sternal variations and anomalies are rarely reported in the African population. A prevalence of $37.6 \%$ of anatomical variations of the sternal angle has been recently reported in Kenya [8]. In another Kenyan study, sternal foramina and bifurcation of the xiphisternum were found in $11(13.8 \%)$ and $10(12.5 \%)$ cases respectively [7]. Of the 11 sternal foramina, $9(81.8 \%)$ was on the sternal body, where they predominantly occurred at the fifth intercostal segment [7]. With the increasing road traffic crash-related trauma in Uganda [2], it is important for clinicians to be aware and suspicious of the aforementioned variations and anomalies so as to avoid misdiagnosis as fracture or traumatic fissure. However to the best of our knowledge, there is limited work done on sternal anomalies in Uganda, with only a single sternal variation in a case study previously reported [16]. Yet these variations and abnormalities may influence clinical procedures and diagnosis such as intercostal nerve blocks, interpretation of sternal images and evaluation of chest trauma, among other thoracic procedures and diagnostics $[7,8,21]$.

The current study therefore aimed to determine the anatomical variations of the sternal angle and anomalies of the sternum among adult human sterna in the Galloway osteological collection at the Department of Anatomy, Makerere University, Uganda.

\section{MATERIALS AND METHODS}

The study population consisted of adult human sterna derived from the Galloway bone collection within the Department of Anatomy, Makerere University. Of the 500 human skeletons currently documented in the collection, only 100 sterna were available for investigation at the time of this study. This collection of bones commenced in 1947. They were obtained by maceration of cadaveric specimens and have been in existence for nearly 70 years. All specimens aged 18-45 years with attached manubriosternal symphysis were included in the study. Broken and incomplete sterna as well as those without sex or age record were excluded. According to Gay and Airasian [10], if the known population is 100 or less, then $100 \%$ of that population should be included in the study. Since for this study, the available population was 100 , the sample size for this study was taken as 100 . However, only a total of 85 sterna were utilised (as per the inclusion criteria of this study). For the purpose of the study, the sterna were retrieved from the archives and were scrutinised for viability and whether they met the inclusion criteria. Demographic details (age and sex) were obtained from the catalogue of bones in the Anatomy Laboratory. 


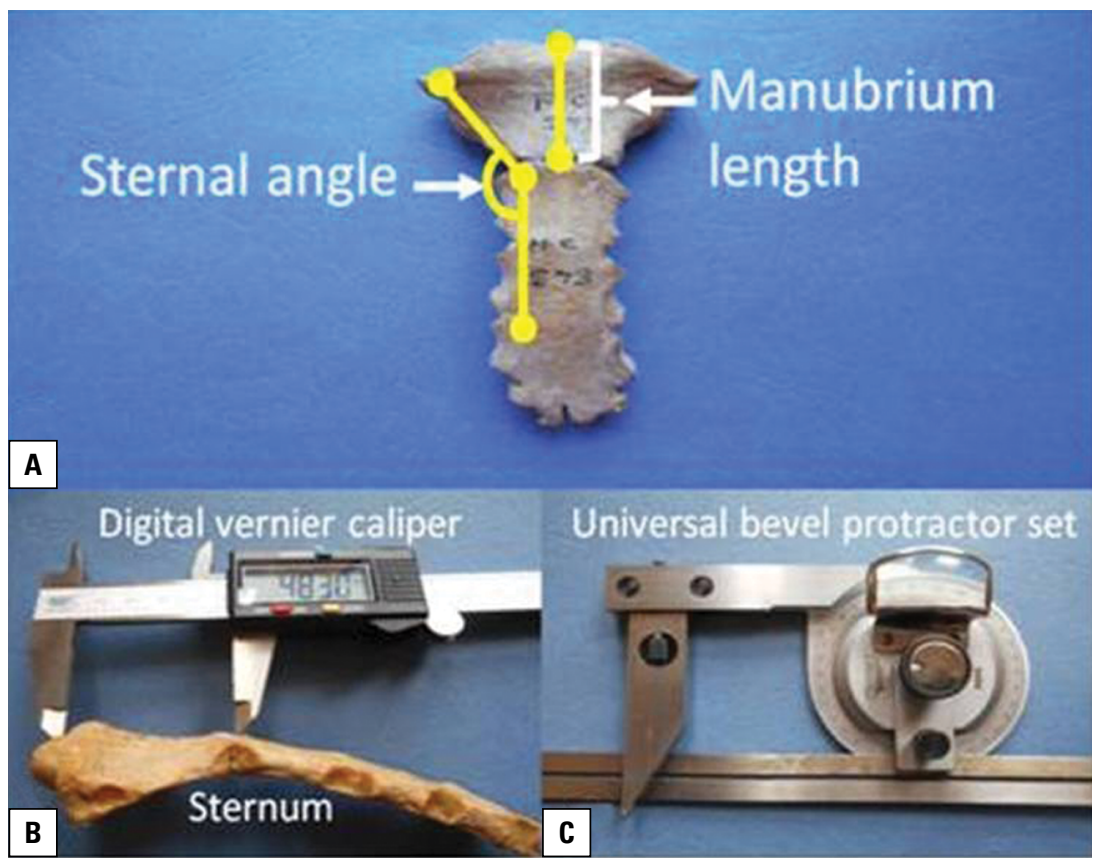

Figure 1. A. Photograph showing the landmarks used in measuring the sternal angle and manubrium length; B, C. Photograph illustrating the instruments used in the study.

The sternal angle was measured on a flat surface using three landmarks: a point immediately below the inferior end of clavicular notch, one immediately below manubriosternal junction, and a point inferior to the fourth costal notch [21]. Two lines were drawn to join these points (Fig. 1A) and the angle subtended was measured using a Draper Expert 52430 universal bevel protractor set (Draper Tools LTD, Hampshire, UK: accuracy $\pm 0.5^{\circ}$; Fig. $1 \mathrm{C}$ ). Manubrium length, on the other hand, was measured from the centre of the jugular notch to the centre of the sternal synchondrosis (Fig. 1A), as previously reported [21], using a Draper Expert 52427 digital vernier calliper (Draper Tools LTD, Hampshire, UK: accuracy \pm 0.01 mm; Fig. 1B). Measurements were taken by two observers at two separate sittings and averages recorded. Any angle out of the reference interval of $155-175^{\circ}$ and any manubrium longer than $58.8 \mathrm{~mm}$ in males and $56.9 \mathrm{~mm}$ in females were considered exaggerated and abnormally long, respectively [21]. The location of the angle and number of sternal symphyses were also recorded. The sternal angle was considered misplaced if it did not correspond with the second costal notch. Photographs of representative sterna were taken using a Coolpix S2900 digital camera (Nikon Corporation, Tokyo, Japan) with a resolution of 20.1 megapixels. Data was analysed using SPSS version 21.0 (Windows $^{\mathrm{TM}}$ Inc., Chicago, USA) and from general descriptive statistics, means and standard deviations of the measured parameters were derived. The level of agreement in the readings of the two observers was determined using Cohen's kappa statistics (k). The sex differences were determined using independent Student's t-test and a $p$ value of $\leq 0.05$ was considered significant. Ethical approval was obtained from the Makerere University School of Biomedical Sciences Higher Degrees Research and Ethics Committee (approval number SBS 308) before commencement of the study.

\section{RESULTS}

The two observers agreed moderately $(\mathrm{k}=0.621$, $p=0.000)$ and strongly $(k=1.000, p=0.000)$ in the respective readings of the size of the sternal angle and manubrium length. Of the 85 specimens examined, only $21(24.7 \%)$ had a xiphoid process. More than three quarters of the specimens were between 21 and 40 years old $(70 / 85,82.4 \%)$ and were males $(75 / 85$, $88.2 \%$ ). The mean age was $32 \pm 6.9$ years with a standard error of the mean (SEM) being 0.7. The sternal angle ranged from $149.0^{\circ}$ to $177.0^{\circ}$ with an average of $163.4 \pm 6.7^{\circ}$ in males and $165.0 \pm 6.4^{\circ}$ in females. This difference was however not statistically significant $(p=0.481,95 \% \mathrm{Cl}-6.07$ to 2.88 ). Average manu- 
Table 1. Sternal variations $(\mathrm{n}=85)$

\begin{tabular}{lcc}
\hline Variations & Frequency & Per cent \\
\hline Exaggerated size of sternal angle & 12 & $14.1 \%$ \\
Misplaced sternal angle & 1 & $1.2 \%$ \\
Additional sternal symphysis & 6 & $7.1 \%$ \\
Fused manubriosternal symphysis & 8 & $9.4 \%$ \\
Fused xiphisternal symphysis & 9 & $10.6 \%$ \\
\hline
\end{tabular}

Table 2. Sternal anomalies

\begin{tabular}{lcc}
\hline Anomalies & Frequency & Per cent \\
\hline Sternal fissure $(\mathrm{n}=85)$ & 7 & $8.2 \%$ \\
Sternal cleft $(\mathrm{n}=85)$ & 7 & $8.2 \%$ \\
Sternal foramen $(\mathrm{n}=85)$ & 11 & $12.9 \%$ \\
Bifid xiphoid $(\mathrm{n}=21)^{*}$ & 9 & $42.9 \%$ \\
Perforated xiphoid $(\mathrm{n}=21)^{*}$ & 2 & $9.5 \%$ \\
Abnormally long manubrium $(\mathrm{n}=85)$ & 1 & $1.2 \%$ \\
Sternal tubercles $(\mathrm{n}=85)$ & 6 & $7.1 \%$ \\
\hline
\end{tabular}

*Percentage figures for bifid and perforated xiphoid were computed basing on $n=21$, since only 21 specimens had a xiphoid process.

Table 3. Population differences in the size of sternal angle

\begin{tabular}{|c|c|c|c|}
\hline Author & Population & $\begin{array}{l}\text { Sample } \\
\text { size }\end{array}$ & $\begin{array}{l}\text { Mean sternal } \\
\text { angle }\left({ }^{\circ}\right)\end{array}$ \\
\hline Selthofer et al. [21] & Croatians & 90 & $\begin{array}{c}M=166.4 \pm 7.4 \\
F=165.3 \pm 7.2\end{array}$ \\
\hline El-Busaidy et al. [8] & Kenyans & 80 & $\begin{array}{c}M=161.7 \pm 6.0 \\
F=159.9 \pm 5.9\end{array}$ \\
\hline Present study & Ugandans & 85 & $\begin{array}{c}M=163.4 \pm 6.7 \\
F=165.0 \pm 6.4\end{array}$ \\
\hline
\end{tabular}

$\mathrm{M}$ - male; F - female

brium length, on the other hand was not significantly different, at $46.0 \pm 5.0 \mathrm{~mm}$ and $43.9 \pm 3.8 \mathrm{~mm}$ in males and females ( $p=0.208,95 \% \mathrm{Cl}-1.19$ to 5.37 ), respectively. Manubriosternal fusion occurred slightly earlier (31.9 \pm 6.0 years) than xiphisternal fusion (33.8 \pm 8.9 years). A number of sternal variations (Table 1) and anomalies (Table 2) were also identified.

\section{DISCUSSION}

The authors set out to determine the anatomical variations of the sternal angle and anomalies of the sternum among adult human sterna at the Galloway osteological collection. Exaggerated size of the sternal angle (Table 1) and bifid xiphoid (Table 2) was

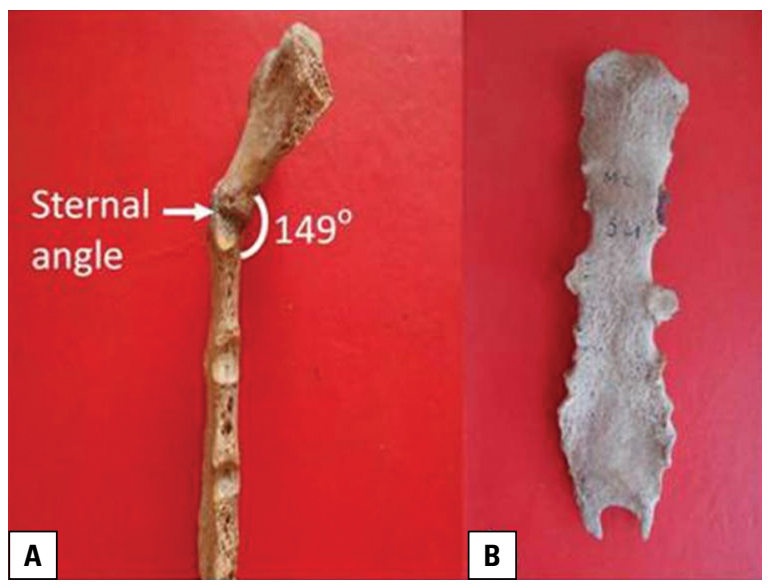

Figure 2. Photographs illustrating selected sternal variations; A. Sternal angle of size $<150^{\circ}$ (grossly exaggerated); B. Completely fused manubriosternal and xiphisternal symphyses.

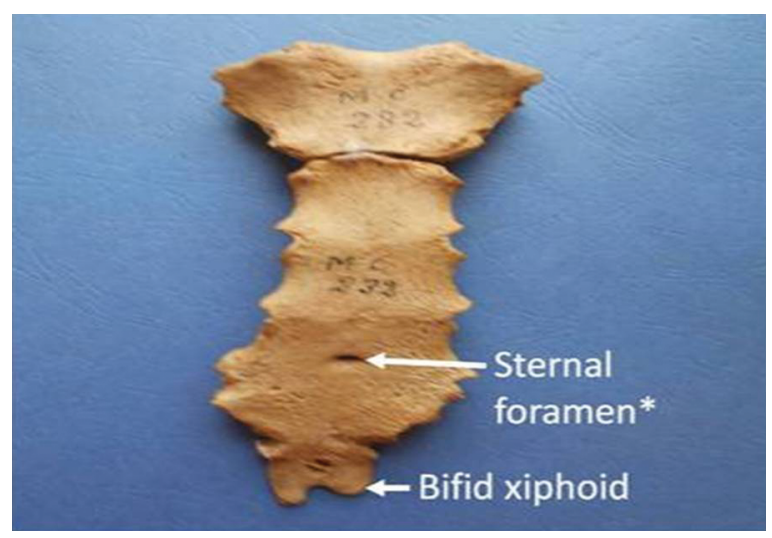

Figure 3. Photograph illustrating selected sternal anomalies; *Foramen is at the inferior third of the sternal body.

the most prevalent sternal variation and anomaly, respectively. A review of literature found two studies $[8,21]$ that have documented the size of the sternal angle, one in Kenya and the other in Croatia (Table 3). Table 3 depicts variant sizes of the sternal angle across populations with Ugandan and Kenyan sterna being smaller than Croatian sterna. This difference may be attributed to geographical variations in the size of the angle and probably body mass index, as sample size and methodology used in these studies were similar. Furthermore, the present study found $1(1.2 \%)$ case of grossly exaggerated sternal angle measuring less than $150^{\circ}$ (Fig. 2A). This variant has been associated with sternal fractures in mild trauma to the anterior chest wall $[3,5]$. Sternal fractures commonly result from motor vehicle collisions, particularly in restrained 
front seat occupants [18]. Some studies have shown that up to $8 \%$ to $10 \%$ of hospitalised patients with blunt chest trauma had sternal fractures $[12,13]$. This warrants extra caution when evaluating anterior chest wall trauma. Bifurcated xiphoid (Fig. 3) has also been reported in $19(1.9 \%)$ subjects [27], far from what has been enumerated in the present study (Table 2). This disparity may be, in part, attributable to racial differences between the populations. Nevertheless, this anomaly may raise alarm for xiphoid fracture [7] and may therefore be considered a differential.

Sternal fusions are important in forensic medicine for age estimation $[17,20]$. Complete manubriosternal and xiphisternal fusions were observed in the present study (Fig. 2B), with manubriosternal fusion occurring slightly earlier ( $31.9 \pm 6.0$ years) than xiphisternal fusion (33.8 \pm 8.9 years). This finding conflicts what is known to most forensic experts, where xiphisternal fusion occurs earlier than manubriosternal fusion and at much later stages of life. Literature in forensic medicine $[17,20]$ describes fusion of xiphoid process with mesosternum at about 40 years of age and that of manubrium and mesosternum at "very old age" i.e. 55-60 years. However results of studies, each with variant statistics, have disagreed with these assumptions $[6,14,22,23,25,27]$. In view of such diverse and conflicting opinions, studies need to be done for specific populations to generate specific data for forensic use in such populations. With the exception of the present study and a Turkish study by Yekeler et al. [27], the rest of the studies reporting on manubriosternal and xiphisternal fusions cited here were conducted among Indians. Hence racial differences may be playing a role in the disparities seen.

Sometimes, there is an opening in the body of the sternum called the sternal foramen. This common defect results from abnormal ossification and is of no clinical significance, except that its presence should be identified so that it will not be misinterpreted on a thoracic radiograph as a bullet hole [15]. However, sternal foramina may pose a great hazard during sternal biopsy, due to inadvertent pericardial or great vessel puncture $[1,26]$. They can also be misinterpreted as osteolytic lesions in cross-sectional imaging of the sternum $[1,6,19]$. Fatal cardiac tamponade resulting from congenital sternal foramen located in the inferior part of the sternum was seen during sternal puncture for bone marrow biopsy or acupuncture $[11,26]$. This calls for avoidance of the inferior parts of the sternum during bone marrow aspiration.
In 2006, sternal foramen located in the corpus was found in 45 (4.5\%) subjects by Yekeler et al. [27]. All were present in the inferior part of the sternal body, as were cases identified in the present study (Fig. 3). The statistics were, however, not consistent with those of the present study (Table 2). This disparity may be attributed, in part, to the methodological differences between the two studies as Yekeler et al. [6] used a multi-detector computed tomography scan to study sterna of 1,000 living individuals in Turkey.

\section{Limitations of the study}

This study was limited by a small sample size which may affect the generalisability of our findings. Being an institution-based study, the findings may not portray a good picture of the general Ugandan community, and there may be a tendency for self-selection of cases brought to the study institution. Hence anatomical variations of the sternal angle and anomalies of the sternum may be under- or over-reported since potential cases of variations and anomalies within the community may have been excluded or included when assembling the 500 skeletons. A non-random sample was used due to limited specimens in the study department and institution. This may introduce selection bias in the study, similarly leading to over- or under-reporting of sternal variations and anomalies.

\section{CONCLUSIONS}

Sternal variations and anomalies are prevalent in the Galloway osteological collection. Over $40 \%$ of the specimens had variations in size, location and fusion of the sternal angle. Bifid xiphoid (42.9\%), followed by sternal foramen (12.9\%), were the most frequent sternal anomalies in this collection. There is need for increased awareness of these findings as they may determine the accuracy of clinical and other procedures in the thoracic region.

\section{Acknowledgements}

We are grateful to the then Chair, Department of Anatomy, Makerere University, Prof. Joseph Ochieng for permission to collect data from Galloway osteological collection, and to the African Development Bank-Higher Education Science and Technology (AfDB-HEST) Research Support Project that funded this study.

\section{REFERENCES}

1. Babinski MA, de Lemos L, Babinski MSD, et al. Frequency of sternal foramen evaluated by MDCT: a minor varia- 
tion of great relevance. Surg Radiol Anat. 2015; 37(3): 287-291, doi: 10.1007/s00276-014-1339-x, indexed in Pubmed: 25023390.

2. BakamaNume, BB "Road Traffic Accidents in Uganda: Epidemiological and Transport Policy Implications", African Social Science Review: Vol. 3: Iss 3 2006: Article 2.

3. Baubin M, Rabl W, Pfeiffer KP, et al. Chest injuries after active compression-decompression cardiopulmonary resuscitation (ACD-CPR) in cadavers. Resuscitation. 1999; 43(1): 9-15, doi: 10.1016/S0300-9572(99)00110-0, indexed in Pubmed: 10636312.

4. Cubuk S, Hamcan S. Anatomic variations of sternum may mimic traumatic complications. Am J Emerg Med. 2016; 34(9): 1912.e1-1912.e2, doi: 10.1016/j. ajem.2016.01.026, indexed in Pubmed: 26905807.

5. de Waele J, Calle P, Blondeel L, et al. Blunt cardiac injury in patients with isolated sternal fractures: the importance of fracture grading. Eur J Trauma. 2002; 28(3): 178-182, doi: 10.1007/s00068-002-1136-9.

6. Duraikannu C, Noronha OV, Sundarrajan P. MDCT evaluation of sternal variations: Pictorial essay. Indian J Radiol Imaging. 2016; 26(2): 185-194, doi: 10.4103/09713026.184407, indexed in Pubmed: 27413263.

7. El-Busaid H, Kaisha W, Hassanali J, et al. Sternal foramina and variant xiphoid morphology in a Kenyan population. Folia Morphol. 2012; 71(1): 19-22, indexed in Pubmed: 22532180.

8. El-Busaidy H, Hassanali J, Kaisha W, et al. Prevalence of abnormal sternal angles in a Kenyan population. Anat Physiol. 2014; 4(1): 135, doi: 10.4172/2161-0940.1000135.

9. Fokin AA. Cleft sternum and sternal foramen. Chest Surg Clin N Am. 2000; 10(2): 261-276, indexed in Pubmed: 10803333.

10. Gay LR, Airasian P. Educational Research Competencies for Analysis and Application, 7th ed. Upper Saddle River, NJ: Merrill, Prentice Hall, Chapter 102003.

11. Halvorsen TB, Anda SS, Naess AB, et al. Fatal cardiac tamponade after acupuncture through congenital sternal foramen. Lancet. 1995; 345(8958): 1175, doi: 10.1016/ S0140-6736(95)91004-2, indexed in Pubmed: 7723561.

12. Harley DP, Mena I. Cardiac and vascular sequelae of sternal fractures. J Trauma. 1986; 26(6): 553-555, indexed in Pubmed: 3723623.

13. Hills MW, Delprado AM, Deane SA. Sternal fractures: associated injuries and management. J Trauma. 1993; 35(1): 55-60, indexed in Pubmed: 8331713.
14. Jit I, Bakshi V. Time of fusion of the human mesosternum with manubrium \& xiphoid process. Indian J Med Res. 1986; 83: 322-331, indexed in Pubmed: 3733193.

15. Moore KL. Thorax: Clinically Oriented Anatomy, 7th ed. Lippincott Williams and Wilkins, Philadelphia 2013: 41-42.

16. Ochieng J, Ibingira CBR. Sternal Anomalies with Supernumerary and Subnumerary Vertebrae and Ribs Case Reports. Association of Surgeons of East Africa and College of Surgeons of East Central and Southern Africa. 2007; 12(1): 99-104.

17. Parikh CK. Parikh's Textbook of Medical Jurispendence and Toxicology. Medical Publications 2005: 2.9-2.10.

18. Pattimore D, Thomas $\mathrm{P}$, Dave SH. Torso injury patterns and mechanisms in car crashes: an additional diagnostic tool. Injury. 1992; 23(2): 123-126, doi: 10.1016/00201383(92)90047-V, indexed in Pubmed: 1572708.

19. Pevenage $P$, Maeseneer $M$, Muylle $K$, et al. Sternal foramen simulating osteolytic lesion on scintigraphy and SPET imaging. Ann Nucl Med Sci. 2002; 15: 227-230.

20. Reddy KSN. The Essentials of Forensic Medicine and Toxicology. Medical Book Company 2006: 25, 67.

21. Selthofer R, Nikolić $V$, Mrcela T, et al. Morphometric analysis of the sternum. Coll Antropol. 2006; 30(1): 43-47, indexed in Pubmed: 16617574.

22. Singh D, Jit I. Sanjeev Time of fusion of mesosternum with manubrium and xiphoid process. J Ant Soc India. 1994; 43: 125-135.

23. Singh TB, Singh C, Fimate L. Age determination from the degree of fusion of manubrio-mesosternal joint. J Forensic Med Toxicol. 2004; 21(1): 15-18.

24. Skandalakis J, Colborn G, Weidman T, et al. Thoracic wall and pleura: Skandalakis Surgical Anatomy, McGraw-Hill, Chapter 2, 2006.

25. Wadhawan M, Murari A, Murali G. Estimation of age from the fusion of mesosternum with manubrium and xiphisternum in Delhi: A comparative study. J Indian Acad Forensic Med. 2009; 31(2): 103-6.

26. Wolochow MS. Fatal cardiac tamponade through congenital sternal foramen. Lancet. 1995; 346(8972): 442, doi: 10.1016/S0140-6736(95)92814-6, indexed in Pubmed: 7623587.

27. Yekeler $E$, Tunaci $M$, Tunaci $A$, et al. Frequency of sternal variations and anomalies evaluated by MDCT. AJR Am J Roentgenol. 2006; 186(4): 956-960, doi: 10.2214/ AJR.04.1779, indexed in Pubmed: 16554563. 